\title{
The use of slotted - displacement ceiling diffuser in rooms with stationary workplaces with computer equipment
}

\author{
Agnieszka Zając $\mathrm{c}^{1, *}$ \\ ${ }^{1}$ Wroclaw University of Science and Technology, Faculty of Environmental Engineering, \\ Department of Air Conditioning, Heating, Gas Engineering and Air Protection, ul. Norwida 4/6, \\ 50-373 Wroclaw, Poland
}

\begin{abstract}
This paper presents a specification of premises with a stationary workstations. An analysis of thermal loads occurring in a public utility rooms equipped with a computer, electronic and multimedia equipment was carried out. Attention was drawn to an annual occurrence of a positive heat balances in an occupied workstations and heat losses in winter time in unoccupied premises. For an air distribution a slotted displacement ceiling diffuser was proposed, used for mixing ventilation (MV) in up-up type of air exchange in room. The results of measurements in the form of air flows in the area of its operation are provided. The graphs show the graphical distribution of air velocities and temperatures in the vertical plane passing through the transverse axis of the air diffuser. The study focused on one of the representative airflow of supply air and the behaviour of the air stream during heating and cooling was presented.
\end{abstract}

\section{Introduction}

Nowadays, specialised workstations fitted with a computer equipment are often designed. Such workplaces are located in buildings for educational purpose (computer rooms at universities, in schools, in educational centres), in offices (training rooms in banks, telecommunications), in entertainment (gaming rooms, internet cafes) and even production (rooms for regulation and control of technological processes or monitoring and supervision rooms).

Such computer rooms require efficiently operating ventilation or air conditioning installations [1]. The presence of a large number of people and computer equipments causes a significant deterioration of air quality, and in the absence of efficient air-conditioning contributes to the reduction of user concentration and reduced performance [2]. While favourable microclimate conditions positively affect the well-being, improve the reception of information and, as a result, the desired increase in work efficiency [3, 4]. Creation of conditions in which a person would feel a state of thermal comfort is the main goal of installing air conditioning devices [2].

\footnotetext{
* Corresponding author: agnieszka.zajac@pwr.edu.pl
} 
The most important factors of the room's microclimate are the thermodynamic air parameters and velocity in people's occupancy area [5]. In workplaces, both the temperature and a relative humidity of the air should be shaped. This means that the air should be heating and humidification in a winter time, and a cooling and dehumidification in the summer, in HVAC systems.

The condition of people's well-being in public premises with the use of mechanical ventilation, or air conditioning, is determined by the correct calculation of the ventilating air stream and the proper solution for distributing this air in the room [6]. With an improperly designed flow, a significant part of the supplied air may not take part in the assimilation of unnecessary heat gains. The result of this is the creation in the room of the so called air dead zones or areas with uneven temperature distribution. The current state of air conditioning technology allows to prepare air of any parameters, solve the most complicated installation systems and link them with automatic control devices and control and measurement apparatus. However, it is difficult to obtain a proper and effective distribution of air in the room $[1,7]$.

In computer rooms, the most reasonable is to bring fresh air directly into the people's area [8-10]. This solution is related to a down-up type of air exchange in rooms (displacement ventilation, DV or stratum ventilation, SV) [11]. In the case of computer rooms, this solution can be difficult to implement. This applies in particular to architectural and construction limitations related to distribution of air installations and the installation of a supply elements. Often, there are several computers installed in a relatively small area, where the height of the rooms does not exceed 3.0-3.5 m. In such situation, the use of a part of the height for installing an additional floor to make the space for running air installations (air ducts) may be unacceptable. In addition, maintaining the cleanliness of floors, so that the air does not entrain dust particles, is often difficult to implement, especially when the air-conditioned room is a room in an academic building [12, 13]. Students/pupils change every 45 or 90 minutes and often enter the room almost straight from the street.

The air flow from the top to the bottom is unfavourable when the supplied air mixes with the conventionally carried out streams of used air (air which assimilated heat and moisture from people and other sources) [14]. However, it is possible to resolve the supply elements and such arrangement of diffusers and exhausters in the room so that convection currents from occupants and electronic equipment are used and the thermal sensations of the users are correct. The description of the ceiling diffuser with a limited and properly directed air stream intended for the organisation of up-up air exchange is contained in this paper [15].

\section{Analysis of rooms with stationary workplaces with computer equipment}

Thermal loads of sample computer rooms located on the last floor of one of the Wroclaw University of Science and Technology's buildings were analyzed [16]. In each workstation there are 12 computers installed in the area of $30 \mathrm{~m}^{2}$ (Fig. 1). Thus, there is $2.5 \mathrm{~m}^{2}$ per one computer station. The distance between the workstations is $1.25 \mathrm{~m}$. Due to thermal loads resulting from the location of external walls, the rooms were divided into two zones: with windows on the south-east (SE) and north-west (NW) side. The share of window surfaces in the total habitable and usable area of the room is $15 \%$. Carrying out a detailed analysis of all annual thermal loads, depending on the internal conditions, is an important factor influencing the selection of the air conditioning system [17]. The heat balance values in these rooms change during their use and depend on both internal conditions (number of 
people and equipment and lighting included) as well as external (seasons and day, exterior wall positioning, window type and area, etc.). In the case of premises with an external walls one should expect both - heat gains from solar radiation in a summer and heat losses in a winter time. The architectural and construction solutions of the entire building as well as individual rooms have a significant impact on the heat gains [18]. Of particular importance are the thermal accumulation of the building and the types of transparent divisions used along with their exposure [19]. These factors cause fluctuations in heat gains in individual rooms.

a)

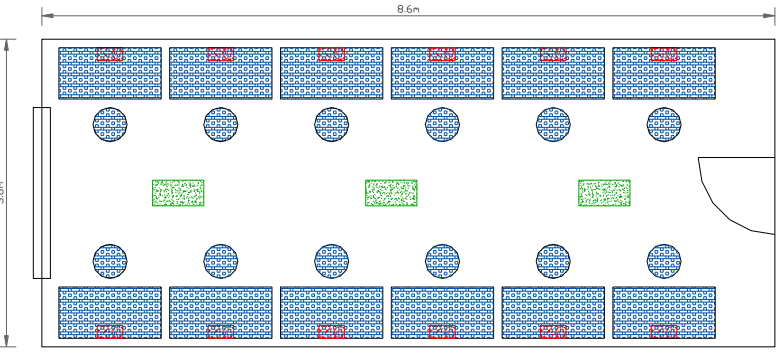

b)

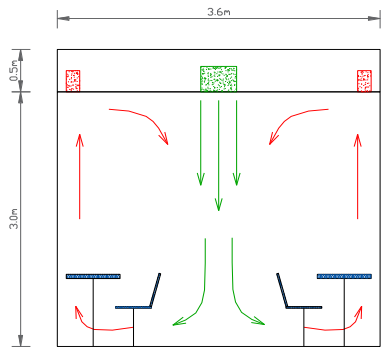

Fig. 1. Localization of computer workstations, supply diffusers and exhaust grills in one of many rooms in Wrocław University of Science and Technology building a) projection of the room, b) vertical section.

The graphics below show the course of heat gains, during the use of the room, from individual sources in a summer time (Fig. 2) and the course of heat gains and losses in a winter time (Fig. 3). When using all computers the heat gains definitely exceed losses and must be assimilated by air conditioning. However, in the period of breaks in the use of the rooms and the lack of heat gains, the occurring heat losses must be compensated. The analysis of thermal loads shows that with the maximum heat gain in the conditions of fixed operation, the basic sources of heat are:

- computers that represent $60 \%$ of the total heat gain,

- users, about $20 \%$ of the total heat gain,

- solar radiation through transparent partitions about 10\%,

- other, for example, electric lighting and non-transparent partitions about $10 \%$.

a) heat gain,

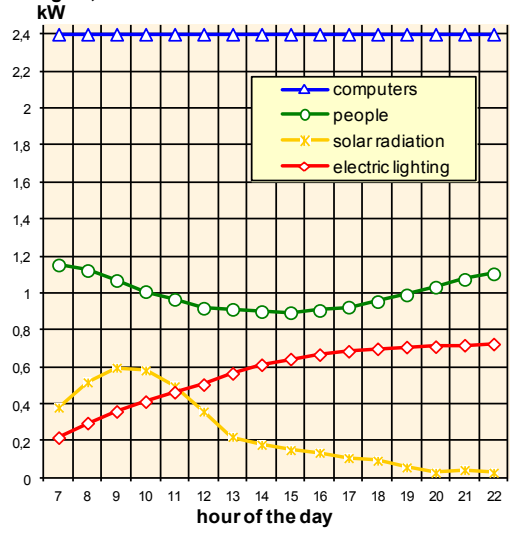

b) heat gain,

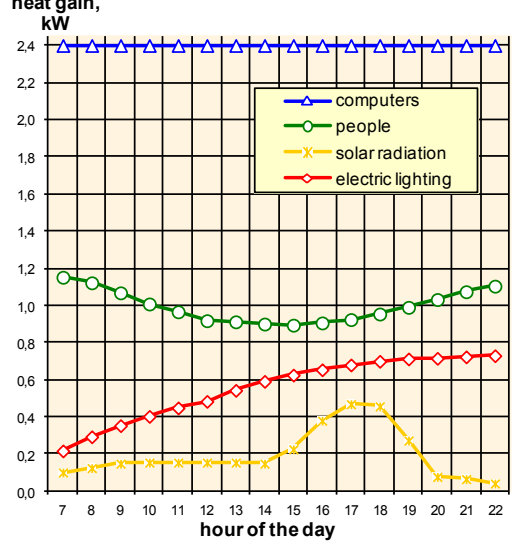

Fig. 2. The course of heat gains from individual sources in a summer time (June) in rooms with windows on the: a) south-east (SE) side and b) north-west (NW) side. 
The quoted heat shares are similar for computer rooms with a similar area per one workplace. It should be noted that the gains of heat from electronic devices and people are changing to a small extent. However, heat gains from other sources are variable. The maximum heat gains in each room are $4.5 \mathrm{~kW}$. Their occurrence time is similar in premises of a given zone, while for premises of a different zones the time of their occurrence is different. In winter time, in unused rooms, at calculated outdoor air temperatures of the winter period (at $-18^{\circ} \mathrm{C}$ ), heat balances may be negative and amount to $-0.75 \mathrm{~kW}$. Then, the heat losses occurring must be covered by air systems or central heating. When using the computer room (at the same time and under the same conditions) heat gains definitely exceed the losses, and the heat balance comes to $50-70 \%$ of the value from the summer period. It should be noted that the heat gain from solar radiation will only be included on sunny days. On cloudy days, these gains will not affect the heat balance.

a)

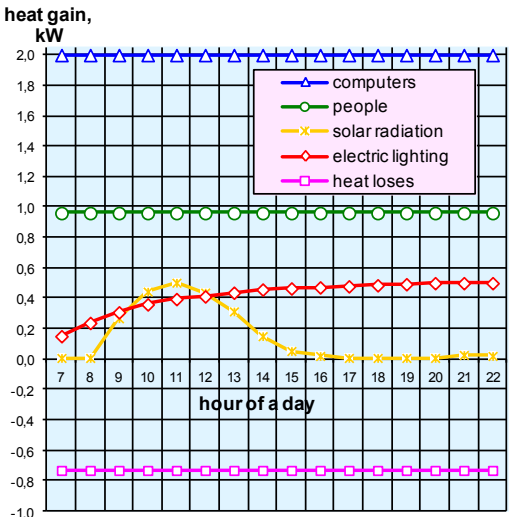

b)

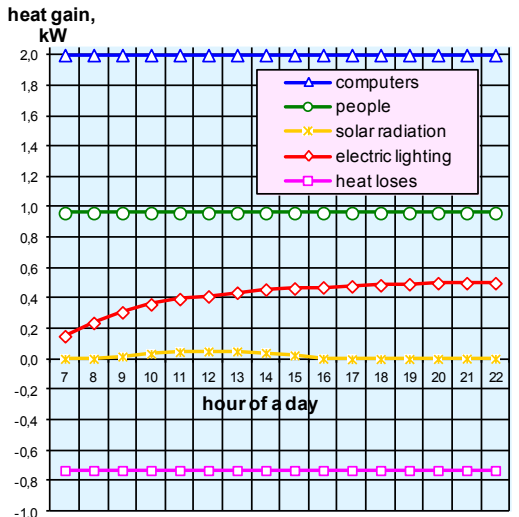

Fig. 3. The course of heat gains from individual sources and heat losses in winter (December) in rooms with windows on the: a) south-east (SE) side and b) north-west (NW) side.

For the analysed computer room, the volume of the air supplied from the ceiling side should be between $1650 \mathrm{~m}^{3} / \mathrm{h}$ to $2200 \mathrm{~m}^{3} / \mathrm{h}$ and from the floor side not less than $4500 \mathrm{~m}^{3} / \mathrm{h}$. This is due to the accepted temperature increases (difference between exhaust and supply air temperature) in the occupied zone (people's area), in order to meet the thermal comfort conditions and do not feel drafts. In each case it provides huge air change rates. The size of flow rates directly affects the dimensions of the distribution ducts and the ventilation or air handling unit (AHU). If the additional temperature gradient were taken into account in the calculations, in the case of high rooms, which would be created above the heat sources, the needed air flow rate could be reduced to $2700 \mathrm{~m}^{3} / \mathrm{h}$ for each room by the ceiling side air supply. And using the creation of convection currents from people and electronic equipment in the organization of up-up type of air exchange with a slotted - displacement ceiling diffuser, the air flow rate could be reduced to $1350 \mathrm{~m}^{3} / \mathrm{h}$.

\section{Measurement station with slotted - displacement diffuser}

The design of the prototype slotted - displacement ceiling diffuser was discussed, among others in [16]. Fig. 4 includes a construction graphic drawing and a view of the diffuser, from which air flows through the centre of perforated surface and two slots, pre-limiting and directing supply air. The air flow rate supplying from the central part of the diffuser is characterized by high inductance and marked turbulence. On the outside, it is limited by air slots that prevent from spreading to the users' heads. By reducing the intense mixing, the air 
stream is brought above the floor, without spreading from side to side, and thus only a small air suction takes place. It begins to stay on the floor, and when meeting heat sources, assimilates their excess and due to convective streams, rises up, straight to the exhaust installation. Such effect of this diffuser has been validated by research in real conditions on a full-scale measurement room in which the real processes were simulated. The advantages of displacement ventilation and down - up type of air exchange by supplying air to the room zone with the smallest unit heat gains and its exhaust from heat sources are used.

a)

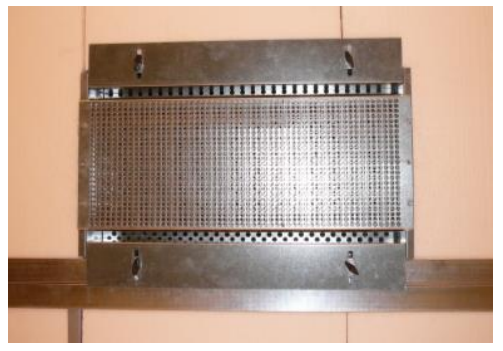

b)

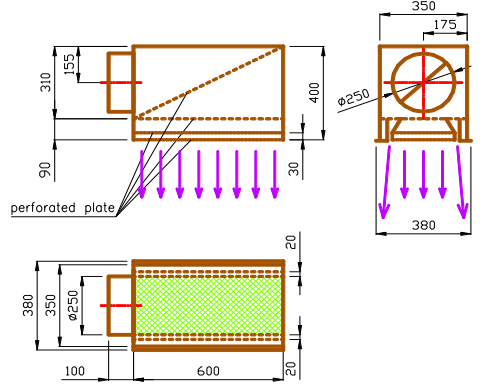

Fig. 4. a) A view, b) construction graphic drawing of the slotted - displacement ceiling diffuser with $20 \mathrm{~mm}$ wide slot.

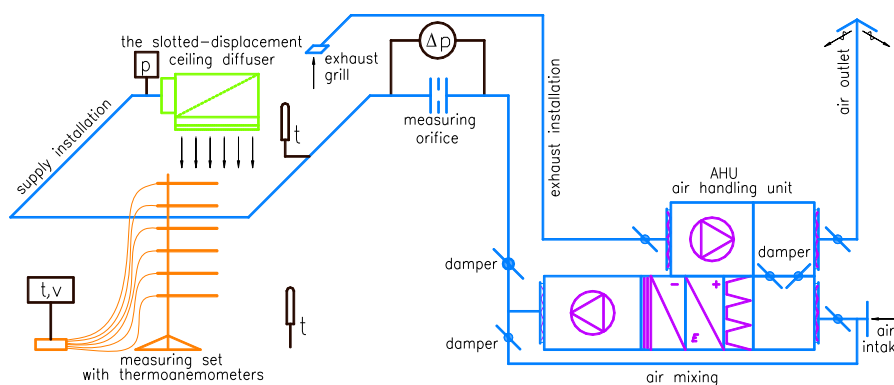

Fig. 5. Graphic diagram of the measurement station with the slotted - displacement ceiling diffuser.

The schematic graphic diagram of the measurement station is shown above in Fig. 5. The ventilation air installation of the researched workstation consists of a supply and exhaust part. The external (outdoor) air or the mixture of external and recycling air (from the room), is prepared in the AHU and transported to the computer room and supplied by a single slotted - displacement diffuser. Depending on the needs, the air will be heated in the electric heater, cooled in a glycol cooler or without heat treatment, introduced into the supply air duct. The air from the room is removed through the ceiling, which is contacted by grids located in the false ceiling.

\section{Air velocity and temperature measurement results}

The study used experimental measurements in a full-scale test room with dimensions of $4 \mathrm{~m}$ width $\times 3 \mathrm{~m}$ length and $2.85 \mathrm{~m}$ height and a HVAC control system. The air velocity and temperature measurements were carried out at different distances from air supply diffuser on measurement station. Sixteen measurement levels were determined at sixteen 
heights from the floor, as presented in Fig. 9 a) (one measurement session consisted of eight heights - left, while measurements in the second session were carried out after moving the tripod core, with fixed probes, by $0.15 \mathrm{~m}$ down - right). The measurements were carried out mainly in the longitudinal and transversal axes of the diffuser containing 29 vertical measuring lines. Measuring grid points have been spaced at intervals of 0.05 or $0.1 \mathrm{~m}$. During the tests, the air flow rates (from 325 to $625 \mathrm{~m}^{3} / \mathrm{h}$ every $75 \mathrm{~m}^{3} / \mathrm{h}$ ), the width of the slot limiting the stream (from 0 to $45 \mathrm{~mm}$ every $5 \mathrm{~mm}$ ), and the degrees of perforation of the outer plate and the internal plates levelling the flow (from 20 to $50 \%$ every $10 \%$ ) were changed. With larger airflow than $625 \mathrm{~m}^{3} / \mathrm{h}$ in the area close to the floor around the people (occupant zone), the velocity exceeded the value of $0.5 \mathrm{~m} / \mathrm{s}$. The share of air flowing through the slots in relation to the total volume of air flow varied from $30 \%$ to $60 \%$. The difference in the result of the subtraction between supply air and room temperature did not exceed $1 \mathrm{~K}$. Such conditions are in fact rare. At very low outside air temperatures, the ventilation/air conditioning unit can also fulfils fully or partially the duty of space heating. Thus, the supply air must have a higher temperature [20]. However, for most of the year it is necessary to assimilate the heat generated by the electronic equipment and users. The supply air temperature must therefore be lower than in the room [21].

The obtained measurement results in the form of a graphic air velocity and temperature distribution (in vertical planes passing through the transverse axis of the diffuser) for air flow rate of $550 \mathrm{~m}^{3} / \mathrm{h}$ are depicted on the diagrams (Figs. 7 and 8 ). The velocity distribution for the transverse axis was chosen because it represents the air flow towards the heads, neck and back of the users/occupants. Extending the stream in the longitudinal direction is not so important. It can only cause an increase in velocity in the transition zone when the diffusers are placed too close to each other. The optimal distance of diffusers, resulting from the width of two computer stations is $2.5 \mathrm{~m}$ which guarantees maintaining the velocity below $0.3 \mathrm{~m} / \mathrm{s}$ in people's area.

a)

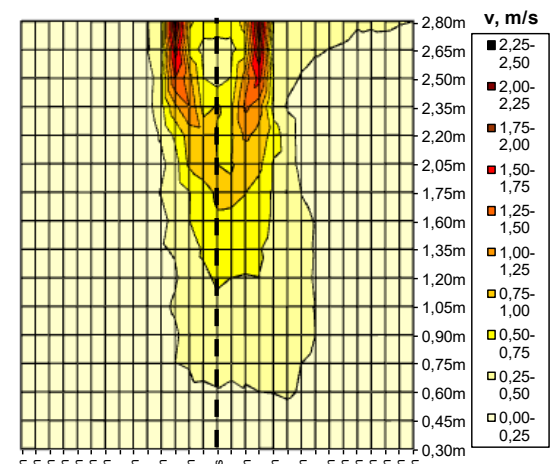

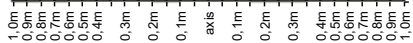

b)

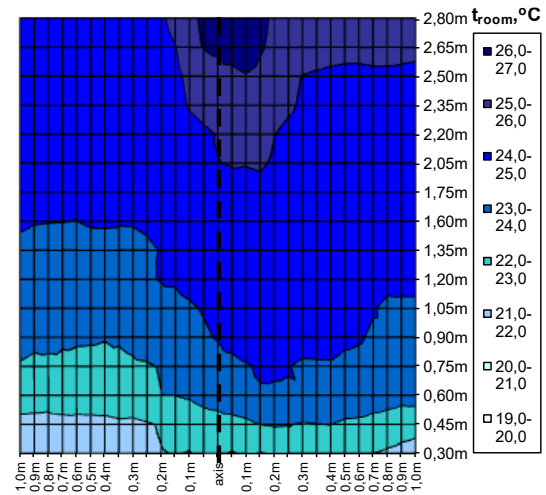

Fig. 7. Distribution of air a) velocity b) temperature in the area of operation of the diffuser during heating of the room (supply air flow rate $550 \mathrm{~m}^{3} / \mathrm{h}$, supply air temperature $27^{\circ} \mathrm{C}$ ). 
a)

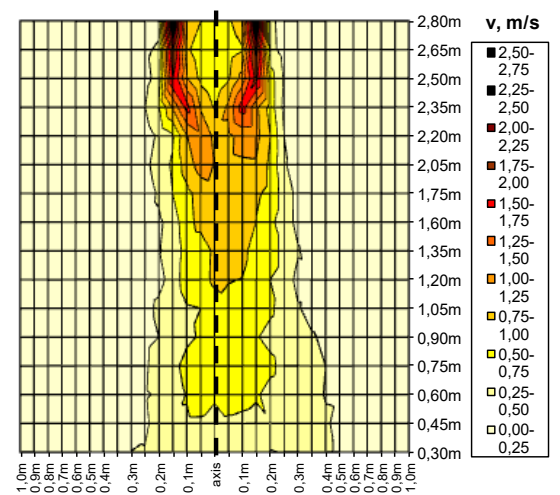

b)

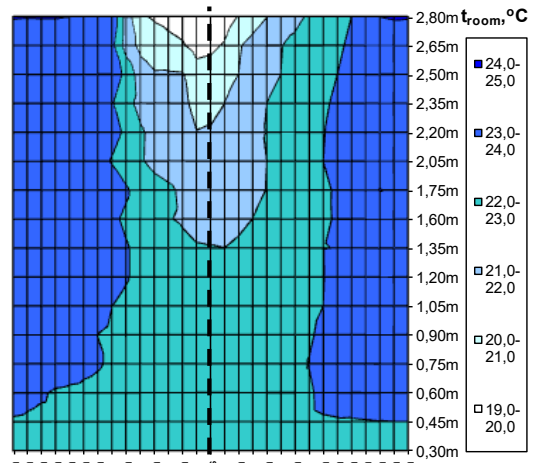

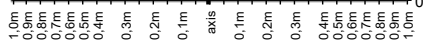

Fig. 8. Distribution of air a) velocity b) temperature in the area of operation of the diffuser during cooling of the room (supply air flow rate $550 \mathrm{~m}^{3} / \mathrm{h}$, supply air temperature $19^{\circ} \mathrm{C}$ ).

The measurements were conducted with attached simulation systems for heat gains from people and computers. Heat sources were placed near the outer walls, away from the diffuser, as it seen in Fig. 9b. The diagrams do not show a cross-section through the entire room. The focus was only on the stream of air supplied from the diffuser. The air velocity distribution and temperature over the heat sources and local convective flows arising there are not shown because it did not come within the scope of research. The range of measurements performed is schematically shown in Fig. $9 \mathrm{~b}$.

The average velocity of supply air from the centre perforated part was in range of 0.45 to $0.85 \mathrm{~m} / \mathrm{s}$, while from the limiting gaps it was from 1.65 to $3.25 \mathrm{~m} / \mathrm{s}$, in the range of tested air flow rates $325-625 \mathrm{~m}^{3} / \mathrm{h}$ and with a constant gap width of $20 \mathrm{~mm}$. A velocity of $0.4-0.8 \mathrm{~m} / \mathrm{s}$ was noted under the diffuser in the people's area. In addition to the area of operation of the diffuser, i.e. where people are continuously present, the velocity did not exceed $0.3 \mathrm{~m} / \mathrm{s}$. The range of increased velocities can be observed in the transition between computer stations, where a person is temporarily staying and moving. A shorter, higher air flow should be perceived by users as refreshing [22]. High velocity zone, so-called zone of influence of the diffuser, was from 0.3 to $0.6 \mathrm{~m}$.

The slotted - displacement diffuser will be useful in rooms with clearly marked passageways, where there will not be a stationary workstation directly under the diffuser.

a)

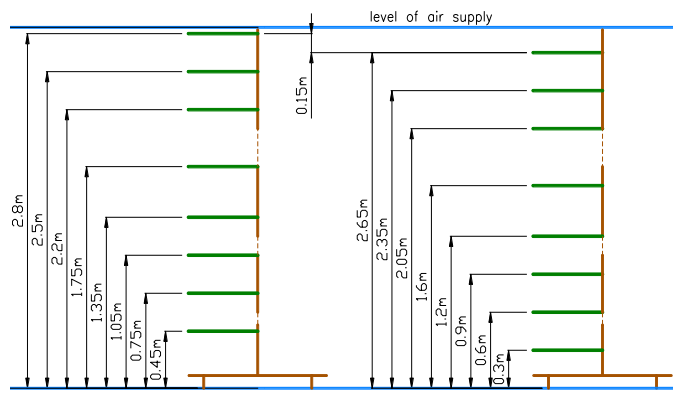

b)

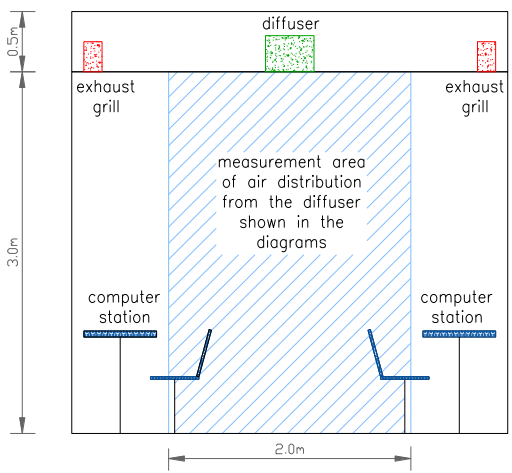

Fig. 9. a) Location of the measurement probes on the stand, b) Measuring range of the stream flowing out of the diffuser into the room (the area of operation of the diffuser). 


\section{Conclusion}

In currently constructed buildings, one may see the premises saturated with an electronic, computer and multimedia equipment, which means that heat gains occur throughout the year. In addition, energy efficient technology for construction of new buildings and good insulation of the external partitions (walls, roof) significantly limit the heat loss or heat gain by heat transfer. Heat deficiencies can occur only in a winter time calculation conditions, and in rooms where internal heat sources are turned off (computers, electric lighting) and where there are no users. Based on the above in 24/7 use of computer rooms, especially without external partitions, there is only a small change to the overall heat balance throughout a year.

In the case of premises with an external walls, insufficiently insulated, both - heat gains from solar radiation in summer and heat losses in winter vary substantially. It should be noted that the heat gains from electronic devices and people are changing in a small extent, they are almost stable. However, heat gains from other sources are variable and depend on external conditions.

It is proposed to use the air exchange system with the slotted - displacement ceiling diffusers of the original construction as an alternative solution to the most recommended systems with supply from a floor level. This paper presents selected results of measurements of the diffuser in non-isothermal conditions. The temperature difference between supplied and room air in both (heating and cooling) cases was about $5 \mathrm{~K}$. The graphical distribution of velocity and air temperature shows the steady and limited air distribution. Although the air flows from the central part of the diffuser are characterised by high inductance and marked turbulence, they are limited by supply air slots preventing from spreading to the users' heads. The advantages of displacement ventilation and the organization of down-up type air exchange can be used due to supplying of air into the room zone with the smallest unit heat gains and its exhausting over concentrated heat sources. Such air movement gives good results in shaping the microclimate of premises with variable and high thermal loads. The measuring diffuser allows for the assimilation of heat similar to that for overhead mixing ventilation (MV) while meeting all the advantages of a positive displacement ventilation (DV) in the area of workplaces and continuous residence of people.

The work was supported by The Faculty of Environmental Engineering, Wroclaw University of Science and Technology, Poland. No. 0401/0055/18.

\section{References}

1. G. Cao, H. Awbi, R. Yao, Y. Fan, K. Sirén, R. Kosonen, J. Zhang, Build Environ. 73, $16(2014)$

1. X. Shan, J. Zhou, W. C. Chang, E. H. Yang, Build Environ. 102, 10 (2016)

2. M. Puteh, M. H. Ibrahim, M. Adnan, C. N. Cheahmad, N. M. Noh, Procedia Soc. Behav. Sci. 46, 5 (2012)

3. Y. Wang, F. Y. Zhao, J. Kuckelkorn, D. Liu, L. Q. Liu, X. C. Pan, Energy 64, 11 (2014)

4. ASHRAE Handbook, HVAC Application (2011)

5. M. H. Fathollahzadeh, G. Heidarinejad, H. Pasdarshahri, Build Environ. 90, 9 (2015)

6. H. B. Awbi, Front Mech. Eng. 1, 4 (2015) 
7. F. Bauman, A. Daly, ASHRAE (2003)

8. R. Becker, M. Paciuk, Build Environ. 44, 13 (2009)

9. M. A. Bos, J. A. Love, Build Environ. 69, 8 (2013)

10. R. Li, S. C. Sekhar, A. K. Melikov, Build Environ. 45, 8 (2010)

11. F. Causone, F. Baldin, B. W. Olesen, S. P. Corgnati, Energy Build. 42, (2010)

12. A. Lipczynska, J. Kaczmarczyk, A. K. Melikov, Build Environ. 92, 12 (2015)

13. H. Ho, L. Rosario, M. M. Rahman, Build Environ. 46, 13 (2011)

14. A. Zając, E3S Web of Conferences 44, 8 (2018)

15. A. Zając, Doctoral thesis, PRE 6, 144 (2008)

16. W. P. Jones, Air conditioning engineering (2001)

17. H. H. Sait, Energ. Convers. Manage. 66, 10 (2013)

18. H. W. Li Danny, L. Yang, J. C. Lam, Energy 54, 10 (2013)

19. H. Amai, A. Novoselac, Build Environ. 109, 11 (2016)

20. B. W. Olesen, A. Simone, M. Krajcík, F. Causone, M. DeCarli, Int. J. Vent. 9, 13 (2011)

21. N. M. Mateus, G. Carrilho da Graca, Build Environ. 114, 13 (2017)

22. R. Tomasi, M. Krajcik, A. Simone, B. W. Olesen, Energy Build. 60, 10 (2013) 